practical rules. Although much of this process has been positive, there are some aspects of it which are not. Each time one encounters a doctor who complains of being treated badly by excessively demanding patients, who has been the subject of groundless and ill-tempered complaints, who has been cast into depression by the prospect of litigation, one is inclined to reflect on the dark side of consumerism and the 'cult' of individual rights. Consumerism, as recent British experience has shown, leads to the shallow world of 'charters', and one wonders whether this is what we need. Perhaps we need more emphasis on obligations, private and public, to balance the talk of rights; we need to re-assert community, however that might be done. The processes which this book reveals all reflect the assertion of individual or sectional interest, and there must be much more debate on this. This well written and intriguing book will serve as an excellent starting point.

ALEXANDER MCCALL SMITH Reader in Law, University of Edinburgh.

\section{Medical confidentiality and legal privilege}

Jean McHale, London, Routledge, 1993, 160 pages, $£ 35.00$

It is one of the nastier dilemmas facing a doctor: he is in the witness box and is asked a question about a patient. If he answers, he breaches the patient's confidence; if he declines to answer, he may be withholding evidence which could deny an accused person the chance of a proper defence. In the background, too, is the consideration that if he fails to answer, he may be imprisoned for his pains. Fortunately, this is not an everyday situation, but it is none the less a problem which does occur on occasion and which raises serious issues for the courts.

English law currently recognises an evidential privilege only in very limited circumstances, and does not extend it to doctors or to those engaged in other professions allied to medicine - Scots law takes much the same view. A lawyer is not compelled to disclose matters which have passed between himself and his client in relation to litigation, and may stay silent with impunity, but a doctor, priest, nurse, psychotherapist or accountant has no such right. It will avail such persons naught that their code of ethics enjoins strict confidence; a failure to answer a relevant question in court will be a punishable offence.

The law has not been completely insensitive to the problem of confidentiality in the past. There have been some suggestions that there is a judicial discretion to exclude evidence relating to confidential matters, and the author cites several remarks by Lord Denning to this effect. Lord Denning, however, was a very special judge - with a marked sympathy for doctors - and if medical privilege is to be introduced it will have to be done by legislation rather than by judicial decision.

There are legal models to follow. Quebec, for example, specifically allows privilege to be claimed by priests, advocates, doctors and dentists, while in some Australian states privilege is allowed at least in relation to civil litigation. In the United States there is considerable privilege accorded to doctors in the witness box, and this is particularly so in the case of psychiatrists.

There are certainly sound pragmatic reasons for allowing medical privilege in court proceedings - the greater the public confidence in medical secrecy the more likely will the public be to trust and confide in doctors (particularly in sexual matters, such as those with a bearing on HIV infection). Yet the real issue here is whether the value of preserving medical confidentiality outweighs the interest which a civil litigant or a defendant in a criminal trial has in having all relevant matters revealed to the court. The author's thesis is that subject to several specific exceptions such as those cases where the welfare of a child is at stake, or where a defendant stands to be convicted of a serious crime - the interest in preserving confidence deserves the greater protection.

If an evidential privilege statute were to be introduced, the effect would be to give the patient a veto on the disclosure in court of medical information which he or she wishes to keep confidential. In her final chapter, the author considers the practical impact of such a statute, and it is here that her case will probably be given its closest examination by lawyers. The author acknowledges potential objections, but points out that in practice courts and tribunals will be able to draw appropriate conclusions even if they are denied access to medical information about a party to proceedings. It will not therefore be fatal to the case of an employer in unfair dismissal proceedings that there is no access to medical records; an employee's patterns of behaviour in the past may provide adequate evidence as to the likely pattern of events in the future. Possibly. In criminal proceedings, the privilege would be overruled, anyway, if the offence were of a sufficiently serious nature, and so there could be no question of privilege causing a miscarriage of justice.

If the impact of an evidential privilege statute were to be so cushioned, then the case for its introduction appears reasonably strong, particularly in view of the dilutions of the principle of confidentiality which seem to be occurring in other contexts. This interesting and well written book sets out the whole issue very clearly and should be a useful addition to the library of those who are interested in confidentiality and the dilemmas it creates.

ALEXANDER MCCALL SMITH Reader in Law University of Edinburgh

\section{A companion to ethics}

\section{Edited by Peter Singer, Oxford, Blackwell, 1993, 565 pages, pb $£ 15.99$}

Do not expect a companion that slips comfortably into the pocket, a ready source of profit and pleasure while queuing at Sainsbury's. This is a large book, with nearly fifty articles informing us about the history of ethics (eastern and western), moral theory, applied ethics and meta-ethics and challenges from such critical standpoints as feminism and marxism. Despite its size, the excellent organisation and layout of the material has resulted in a thoroughly approachable book that is, in general terms, remarkably good value. However, suppose that we ask a more specific question. How useful would this book be to those with little background in philosophical ethics (presumably its principal target) who wish to make a study of problems in medical ethics? We can then focus on the two most pertinent kinds of contribution, those on the relevant parts of applied ethics and those on moral theory. 